\title{
Agronegocios
}

Nota técnica

\section{Análisis económico del cultivo de café en los caseríos de Alto Yacusisa y Alto Belén (José Crespo y Castillo - Huánuco - Perú)}

Economic analysis of coffee cultivation in the hamlets of Alto Yacusisa and Alto Belén (José

Crespo y Castillo - Huánuco - Perú)

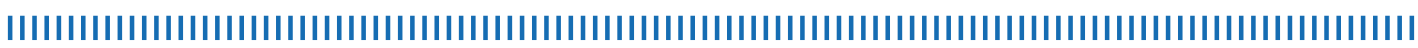

\section{Amanda Ticllacuri Mallqui ${ }^{1}$ Valdemar João Wesz Junior ${ }^{2}$}

Fecha de recepción: 09 de marzo, 2020

Fecha de aprobación: 05 de junio, 2020

Vol.6 No 2 Julio- diciembre 2020

Ticllacuri, A.y Wesz, V.(2020). Análisis económico del cultivo de café en los caserios de Alto Yacusisa y Alto Belén (José Crespo y Castillo- Huánuco-Pe-

rú). Revista e-Agronegocios, 6(2). https://revistas.tec.ac.cr/index.php/eagronegocios/article/view/4993

DOI: https://doi.org/10.18845/ea.v6i2.4993

${ }^{1}$ Universidad Estadual del Oeste de Paraná (Unioeste), Brasil.

Correo electrónico: ticllacurig3@gmail.com ${ }^{2}$ Universidad Federal de la Integración Latino-Americana (UNILA), Brasil. 


\section{Resumen}

El café es un cultivo que creció de manera importante a lo largo de las décadas en Perú, siendo incluso una alternativa introducida más recientemente por el Estado para sustituir la producción ilícita de la hoja de coca. Esta fue la situación que ocurrió en los caserios de Alto Yacusisa y Alto Belén, distrito de José Crespo y Castillo, que pertenecen a la región de Huánuco (Perú). Este trabajo tiene como objetivo realizar el análisis económico del cultivo de café en los caseríos de Alto Yacusisa y Alto Belén (Distrito de José Crespo y Castillo, Huánuco, Perú), para mensurar la ganancia neta obtenida por los agricultores con la producción de café en 2018. Para este trabajo, además de la revisión bibliográfica y análisis de datos secundarios, se encuestaron a 20 cafetaleros (10 de cada caserío). Como resultados, se observa una gran variación de la ganancia por hectárea (ha), siendo que 8 de los 20 productores tienen prejuicio en la actividad. Se percibe que la caída de los precios internacionales del café afecta de manera directa a los productores, en paralelo al alto costo de producción y a las bajas cosechas. Pero, los que consiguen contornar este último punto, son justamente aquellos que obtuvieron mayor ganancia, así como los productores que industrializan su café y venden con un valor agregado. Palabras claves: economía agraria; análisis económico; producción de café; Perú.

\section{Abstract}

Coffee is a crop that grew significantly over the decades in Peru, being even an alternative introduced more recently by the State to replace the illicit production of coca leaf. This was the situation that occurred in the hamlets of Alto Yacusisa and Alto Belén, district of José Crespo y Castillo, which belong to the Huánuco region (Peru). This work aims to perform the economic analysis of coffee cultivation in the hamlets of Alto Yacusisa and Alto Belén (District of José Crespo y Castillo, Huánuco, Peru), to measure the net revenue obtained by farmers with coffee production in 2018. For this work, in addition to the literature review and secondary data analysis, 20 coffee growers were surveyed (10 from each hamlet). As a result, a great variation of the profit per hectare is observed, being that 8 of the 20 producers are prejudiced in the activity. It is perceived that the fall in international coffee prices directly affects producers, in parallel to the high cost of production and low harvests. But, those who manage to contour this last point, are precisely those that obtained greater profit, as well as the producers industrialized their coffee and sold with an added value.

Key words: agrarian economy; economic analysis; coffee production; Peru. 


\section{Introducción}

El café es un cultivo presente en Perú desde el siglo XVIII y, a lo largo de las décadas, se expandió en diferentes regiones, ganando relevancia en el contexto agrícola nacional. En los últimos años ocurrió un crecimiento importante de su producción, llegando a $36 \mathrm{~g}$ mil toneladas en 2018, el doble del año 2000 (MINAGRI, 2019). Este aumento consolida a Perú como el 9mo país productor y el $7 \mathrm{mo}$ exportador en escala global (CÁMARA PERUANA DE CAFÉ Y CACAO, 2017). A pesar de esto, en los años recientes (2014 - 2018), aunque la cantidad exportada creció 50\% (de 180,9 para 268,9 miles de toneladas), el valor generado por este comercio cayó 4\% (de US\$ 727,5 para US\$700,7 millones) (MINAGRI, 2019). Según el Ministerio de Agricultura y Riego (MINAGRI), este resultado es reflejo, principalmente, de la caída de los precios internacionales, sobre todo después de 2011, cuando el precio promedio anual que los productores recibían por el kilo de café estaba en 3,41 US\$/Kg, bajó para 2,43 US\$/Kg en 2014 y llegó a 1,64 US\$/Kg en 2018. Y las perspectivas de los precios internacionales no son favorables, con un deterioro importante hasta mediados de 2019, cuando alcanzo 1,33 US\$/Kg en marzo (MINAGRI, 2019).

Otro desafío que acompaña actualmente el rubro es el cambio climático, que potencializa, por ejemplo, el incremento de las plagas y enfermedades. Un caso que ganó mucha visibilidad fue la enfermedad de "La Roya Amarilla", que en 2012 destruyó alrededor de 94 mil hectáreas de cafetales (originada por el hongo Hemileia vastatrix), agudizando la situación de la producción (MINAGRI, 2019). Y, para combatir las plagas y enfermedades, son necesarias mayores inversiones en el cultivo, que repercute en un costo de producción más alto, y es un riesgo para la ganancia, en un contexto de bajo precio recibido por el producto.

Esto se refleja de manera más intensa entre agricultores que cultivan en pequeña escala, que están mucho más vulnerables y expuestos a los cambios de mercado, ya que existe una competitividad económica que condiciona a aumentar la producción para tener costos progresivamente más bajos, que muchas veces es dificil de ser acompañado por el agricultor que produce en pequeña escala (Conterato et al., 2014). Se suma a esto el hecho de que el pequeño agricultor tiene una "I...] racionalidad económica diferente de los agricultores que producen con una gran escala productiva. Y esta racionalidad económica diferenciada con la que los pequeños agricultores gestionan y ejecutan las actividades de la unidad productiva es uno de los aspectos principales que inciden en el resultado económico de las unidades de producción agrícola" (Conterato et al, 2014, p. 62).

En el caso de los productos integrados a los mercados internacionales esto es aún más intenso, como es el caso del café en Perú, que exporta 90\% de su producción total (La República, 2018). De este modo, las intensas variaciones de precio afectan directamente a los productores de café. Y el hecho de ser un cultivo perenne, que lleva hasta cinco años para producir en su máxima capacidad, dificulta su sustitución por otro cultivo en un año de baja remuneración. Además, la producción tiene que cubrir incluso las inversiones hechas en los años anteriores con la instalación y manejo de los árboles. 
Esta problemática aún es más intensa cuando los productores desconocen los costos de producción, los precios internacionales y la rentabilidad de su producción. Esto ocurre con la mayoría de los pequeños productores cafetaleros de los caseríos Alto Yacusisa y Alto Belén, que pertenecen al distrito de José Crespo y Castillo, departamento de Huánuco (Perú). Una particularidad de estas localidades es que no son tradicionalmente cafetaleras, sino que, después de la erradicación de la hoja de coca que el Estado implantó, los agricultores de los caseríos tenían que elegir un cultivo alternativo y optaron por el café.

El objetivo general de este trabajo es realizar un análisis económico del cultivo de café en los caseríos de Alto Yacusisa y Alto Belén, distrito de José Crespo y Castillo, región de Huánuco Perú, investigando la ganancia neta obtenida por los pequeños agricultores con la producción de café en 2018. La opción por mirar los caseríos limítrofes ocurre porque en Alto Yacusisa solo hay comercialización de café en grano, en cuanto que en Alto Belén hay una asociación que empezó recientemente con procesamiento del café y venta del café molido (listo para el consumo).

El presente trabajo está estructurado en cuatro ítems, además de esta Introducción y de las Consideraciones Finales. Inicialmente, se demuestra la metodología del artículo, seguido por la presentación de algunos datos del cultivo de café en el Perú y en la región de Huánuco. Después se comenta como la producción de café fue introducida en Alto Yacusisa y Alto Belén, destacando algunas características de esta zona y de sus productores. Por fin, se expone el rendimiento del café por hectárea, los costos totales y el precio de venta por hectárea, productor y caserío, calculando la ganancia neta del cultivo.

\section{Metodología}

Para esta investigación fue realizada una revisión bibliográfica sobre los temas del trabajo y análisis de datos secundarios acerca del café en diferentes escalas de Perú. En la secuencia se ha hecho una investigación de campo en los dos caseríos del distrito de José Crespo y Castillo. Según levantamientos en las comunidades, en Alto Yacusisa hay aproximadamente 30 agricultores que se dedican al cultivo de café y en Alto Belén aproximadamente 35 agricultores, de los cuales se entrevistó a 20 productores de café (10 en cada caserio), una muestra correspondiente al 30\% del total. Los 20 entrevistados fueron seleccionados aleatoriamente y todos respondieron una encuesta, con preguntas relacionadas a las caracteristicas de la familia y de la finca y sobre el cultivo del café (producción, costos, precio de venta, canales de comercialización, etc.).

Para un análisis económico del cultivo de café, el primer punto es saber los costos de producción. Para esto, se tomó como base la estructura de cálculo hecha por Parra (2014), que dividió los costos en cinco puntos: a) germinador, almacigo y siembra; b) etapa de crecimiento y producción del café; c) control fitosanitario y cosecha de café; d) procesamiento; e) transporte y comercialización. En el primer punto, se investigó la compra de la semilla, los materiales y herramientas a utilizarse para el germinador, en almacigo y siembra como las bolsas, 
carretillas, mangueras y alambre. En el segundo punto obtendremos información de la mano de obra que se realiza en el manejo y control de malezas del cultivo de café y sobre insumos que utilizan en esta etapa. En el tercer punto se centra en el manejo de plagas y manejo de enfermedades. También integra esta parte la recolección de frutos o cosecha, la cual ocurre en dos épocas del año, que están comprendidas entre los meses de abril y junio, siendo en este periodo la cosecha principal; y entre septiembre y diciembre, que es la cosecha de menor volumen. El cuarto punto aborda el procesamiento del grano de café, que es la etapa que se da después que el grano de café esté seco y presenta una humedad favorable. Después se pila el grano, luego se tuesta, se deja enfriar para moler y, por último, el envasado del café molido. Y el quinto y último punto es sobre el transporte que utilizan para vender su producto al mercado y la comercialización del café trata sobre el tipo de café vendido, a qué tipo de locales es destinado la venta, la cantidad que producen tanto café en grano y molido y a qué precio es vendido.

Es importante comentar que, en el caso de las máquinas y equipamientos, se calculó la depreciación de los mismos. Y en el tema de la mano de obra, se incluyó los gastos con trabajadores de fuera de la finca, no contabilizando en términos económicos los trabajos desarrollados por la familia. Esta opción ocurrió porque los agricultores entrevistados no consideran el costo de oportunidad de su trabajo. Otra observación es que, como el análisis es del año 2018, los costos de implementación del café fueron divididos en 10 años, que es el número de años promedio que una planta de café está en producción.

Con los datos obtenidos, se ha hecho el análisis económico del cultivo de café entre los 20 pequeños agricultores de los caseríos de Alto Yacusisa y Alto Belén. Inicialmente se calculó el costo total de producción, por hectárea, utilizando los elementos descritos arriba. Otra variable clave es el rendimiento del café, que se obtiene a partir de la división de la producción total por la superficie cosechada. Por fin, es necesario tener el valor recibido por el productor por su café, considerando su precio de venta, descontando los gastos de limpieza, almacenamiento, impuestos y transporte hasta el local de comercialización. Con estos datos se calculará la ganancia neta (también conocida como utilidad neta de la producción), que se obtiene multiplicando el precio y el rendimiento, menos el costo de producción. Se considera la ganancia neta (y no bruta) porque se descuentan los gastos administrativos, impuestos, fletes y pérdidas del producto pos cosecha. Estos cálculos están basados en otros estudios hechos en el tema del café (Saldaña, 2019; Gonzalez; Espines, 1980; Cardenas; Cáceres; Carrión; Peña, 2017).

\section{Una mirada hacia el café en Perú y, particularmente, en Huánuco}

En mediados del siglo XVIII ya se producía café en diferentes regiones de Perú, como Chanchamayo, Moyobamba, Jaén, Huánuco y Cusco, tanto para el consumo local como para la exportación (INFOCAFES, 2015). Después de décadas, en que pasaran contextos sectoriales diversos, el último Censo Nacional Agropecuario, de 2012, indica que 223.903 productores se dedicaban al cultivo de café en el país ( $9,86 \%$ del total de fincas peruanas). En términos 
generales, el café es el producto con mayor área en el país. "De las superficies agrícolas con cultivos (4.155.678 hectáreas), destacan las dedicadas tanto a cultivos industriales, como para el consumo humano directo, entre ellos podemos mencionar el café que constituye el 10,2\% del total de superficie" (INEI, 2013, p. 9). A partir del Censo, se puede decir que los productores tienen, en media, 1,9 hectáreas de café cultivado en Perú (INEA, 2013). Una parte importante de la producción de café de Perú está articulada en cooperativas (Becerra Biaggioni, 2010; Weck et al., 2010; Leiva-Espinoza, Peña y Rojas, 2017), así como está creciendo la producción de cafés especiales, o sea, de alta calidad, orgánico, oriundo de microclimas especíicos, con un sabor particular y extraído según estándares rigurosamente establecidos (Castro et al., 2004; Cahuapaza, 2016; Alania Campos, 2018).

La producción del café se realiza con una gran dispersión territorial, que incluye más de 16 regiones, 95 provincias y 450 distritos (INEA, 2013). Según el Censo Nacional Agropecuario del 2012, los productores de café en el Perú están localizados, principalmente, en las regiones de Junín, San Martín, Cajamarca, Cusco, Amazonas y Huánuco. Estos mismos departamentos también detienen la mayor cantidad de superficie (INEA, 2013). La Figura 1, con base en los datos del Censo, permite identificar la localización de la superficie cultivada con café en Perú.

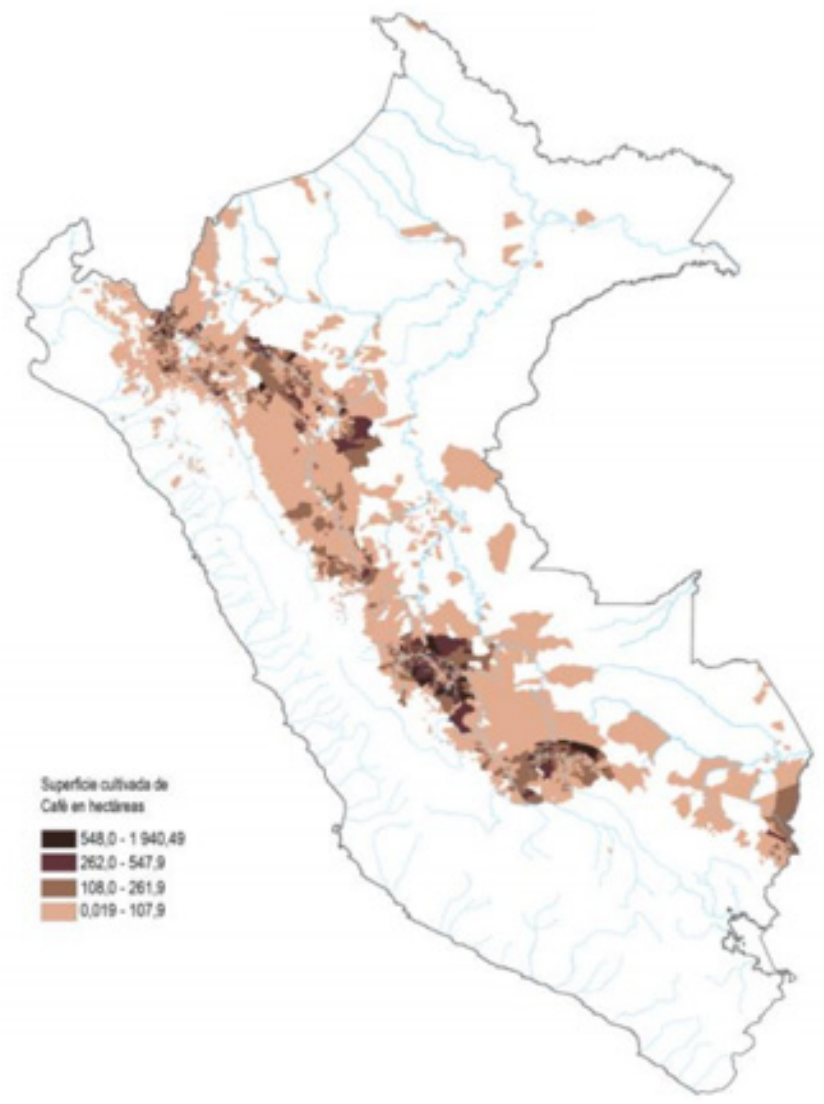

Figura 1 - Mapa de la superficie cultivada de café en los distritos de Perú en 2012

Fuente: IV Censo Nacional Agropecuario de 2012 (INEA, 2013). 
Según datos del Minagri (2019), en Perú hubo un aumento significativo de la producción de café, que aumentó de 97 mil toneladas en 1995 para 352 mil toneladas en 2019 (variación de 264\%). El rendimiento por hectárea creció de manera importante de 1995 hasta 2006 (pasó de $592 \mathrm{~kg} / \mathrm{ha}$ para $834 \mathrm{~kg} / \mathrm{ha}$ ), pero siguió debajo de los $800 \mathrm{~kg} / \mathrm{ha}$ hasta 2011, cuando cae nuevamente la productividad en los años siguientes. Sin embargo, "a partir del 2015 se aprecia una recuperación sostenida de la producción" (MINAGRI, 2019, p. 10).

En términos del precio medio pago al productor por el café, se percibe que eran muy bajos en los años 2002 y 2004 (menor que 1,00 US\$/kg), pero en los siguientes años el precio fue aumentando y alcanzó 3,31 US\$/kg en el año 2011, similar al comportamiento de los precios en el mercado internacional (MINAGRI, 2019). Después de una evolución marcadamente creciente hasta este año, "en los siguientes años se inicia una caída sostenida de dichos precios, en el mercado local e internacional" (MINAGRI, 2019, p. 11). Estos datos apuntan para un contexto sectorial complejo y con grandes desafios para los productores de diferentes zonas de Perú.

Según el Censo Nacional Agropecuario, Huánuco es el sexto mayor departamento productor de café de Perú. En 2012 existían 8.852 productores y era el producto permanente más producido y el segundo entre el conjunto de productos (el lider es la papa, con el doble de área) (INEI, 2013). Es importante decir que, a lo largo de los años, la superficie del café fue expandiéndose en Huánuco, aumentando de 3.937 ha en 2000 para 19.441 ha en 2018 (crecimiento de 394\%) (INEl, 2019). Uno de los motivos de esta ampliación deriva del hecho que el café fue la actividad alternativa al cultivo de la hoja de la coca. Pero, la importante ampliación después de 2010 deriva principalmente del precio de venta del café, que llegó en la región al pico de 3,27 US\$/Kg, incentivando los agricultores a ingresar en el cultivo o ampliar su área (MINAGRI, 2019).

Para tener una estimativa de la ganancia neta del café por año y por área en nivel regional, la Dirección Regional de Agricultura de Huánuco (DRAH, 2019) brinda datos de 2006 hasta 2018. En términos de rendimiento medio de café por hectárea, estima una producción media de $900 \mathrm{~kg} / \mathrm{ha}$ entre 2006 y 2012, que después pasa a $1.100 \mathrm{~kg} / \mathrm{ha}$ (mucho arriba de las medias nacionales). El precio de venta del café se ha mantenido, después del pico en 2011, entre 1,54 y 2,42 US\$ $/ \mathrm{kg}$, con una tendencia de baja de 2014 hasta 2018. Pero, los costos totales de producción crecieron de manera consecutiva a lo largo de los años, saliendo de 885,32 en 2006 para 1.705,69 US\$/ha en 2018 (variación de 102\%) (DRAH, 2019). A partir de la combinación entre rendimiento, precio de venta y costo de producción, se puede decir que la ganancia neta obtenida en una hectárea de café tiene mucha variación conforme el año (Figura 2), tiendo cosechas con muy buenos retornos económicos (2011, 2014 y 2015), en cuanto hay pérdidas en otras (2009, 2016 y 2017). 


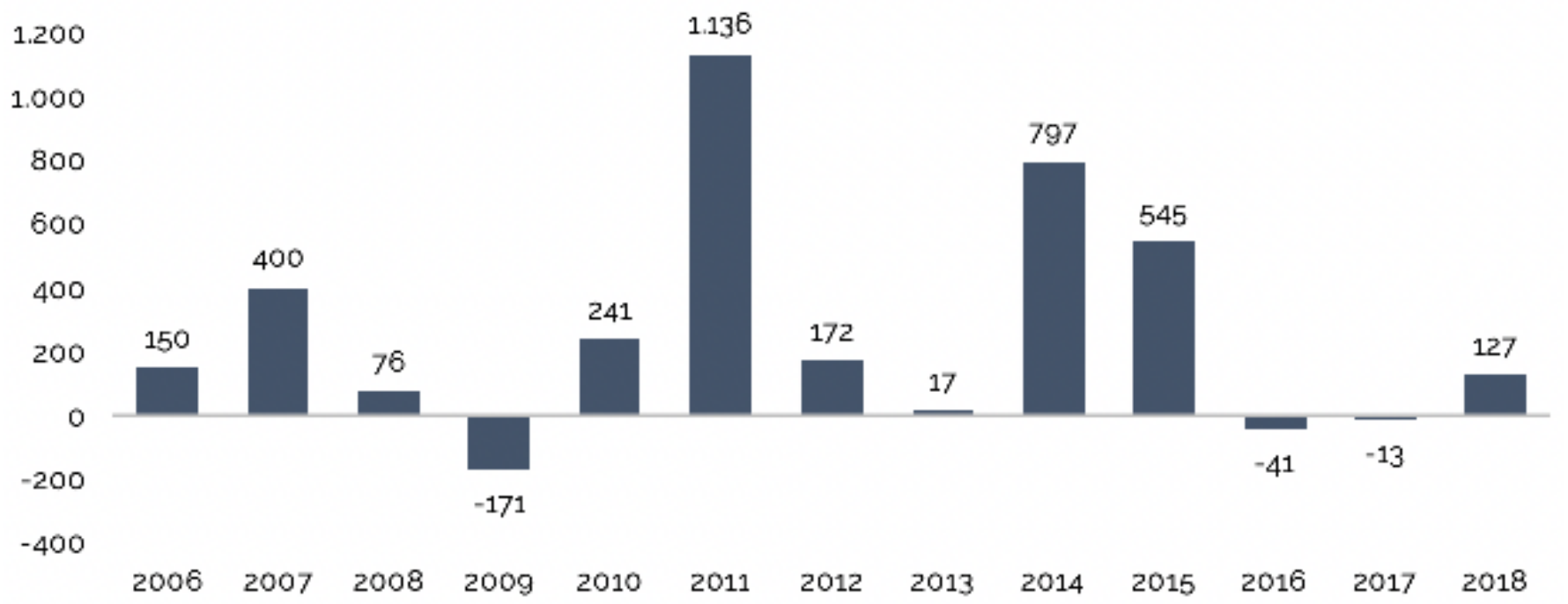

Figura 2- Ganancia neta (US\$) del café por año y por ha en la región de Huánuco

Fuente: Dirección Regional de Agricultura de Huánuco (DRAH, 2019).

Después de esta breve presentación del café a nivel nacional y regional, el foco del trabajo trata sobre los caseríos de Alto Yacusisa y Alto Belén, distrito de José Crespo y Castillo (Huánuco - Perú).

\section{La inserción del café en Alto Yacusisa y Alto Belén}

El distrito de José Crespo y Castillo, localizado a $361 \mathrm{~km}$ de Lima, tenía 5.669 fincas agropecuarias en 2012, con área media de 6 a 10 has, dedicadas principalmente a los cultivos de cacao, café, plátano, naranja, maíz, yuca, piña, aguaje, papaya, cocona, limón y coca (INEI, 2013). En el cultivo de café, en 2012, tenían 1.730 productores, con un área de 2.460 ha, que representa una superficie media de 1,4 ha por agricultor (INEI, 2013).

José Crespo y Castillo tiene 56 caseríos, siendo que Alto Yacusisa y Alto Belén están entre ellos (INEI, 2013). En ambos caseríos la llegada del café fue como un cultivo alternativo a la hoja de coca, después de su erradicación. Para contextualizar, según los comentarios de los entrevistados, en la década del 80 en la región el cultivo de la coca estuvo asociado con el terrorismo y es por esto que el café se fue incrementando en diferentes regiones del país. En el año 1999 en adelante el gobierno implantó políticas internas y externas de lucha contra el narcotráfico y el terrorismo, siendo llamado de Plan Nacional de Desarrollo Alternativo. Este fue un instrumento de lucha contra la pobreza, que no significaba solamente la sustitución de cultivos, sino la puesta en marcha de actividades económicas sostenibles en el tiempo, dando prioridad al mejoramiento de la producción y la recuperación de áreas degradadas e intervenidas, buscando alternativas para el aprovechamiento económico de las áreas poco o 
nada intervenidas, mediante el manejo adecuado de los recursos del bosque, del suelo y de los ríos (URRELO, 1997).

En el caserío de Alto Yacusisa, después de la erradicación del cultivo de la coca, muchos agricultores regresaron a la sierra, es decir, abandonaron sus terrenos en el distrito y se fueron para otras provincias de la región Huánuco. Mientras que los campesinos que decidieron quedarse en sus fincas optaron por el cultivo del café, además de otros productos, como el maíz, arroz, frijoles y cacao (Valera Ríos, 2010). En relación al café, los productores comentan que mucho se les dificultó este cambio del cultivo, ya que la hoja de coca produce a los 4 meses y el café necesita de 3 años. Además, en cuanto el café produce una o dos veces al año ly la segunda con poco rendimiento), la coca tiene una "producción completa" 3 veces al año. Es importante decir que en los primeros años algunos agricultores continuaron con el cultivo de la hoja de coca, pero tuvieron que desistir de ese cultivo ilícito y continuar solamente con los cultivos alternativos que el Estado permitía.

Similar situación ocurrió en el caserío de Alto Belén, donde optaron por el cultivo del café en sustitución a la coca. Pero, los agricultores de ahí son mayormente originarios de Chanchamayo, provincia en que, desde mucho tiempo, se dedican al plantio del café. Entonces, para ellos fue muy rápido adaptarse a este cultivo, por lo que actualmente ya formaron una organización de cafetaleros del caserío y están empezando a vender su producto dándole un valor agregado.

Según levantamiento de campo, en el caserío de Alto Yacusisa viven aproximadamente 35 familias agricultoras, que se dedican a la agricultura para solventar la economía de su familia. Del total, aproximadamente 30 cultivan café, de los cuales se encuestó 10 agricultores para esta investigación. A través de la encuesta se puede observar que la mayoría de ellos están conformados entre 4 a 5 miembros en la familia y se encuentran en un rango de edad entre los 35 a 70 años. En términos de escolaridad, la gran mayoría tienen primaria incompleta, pero algunos son analfabetos y es mínimo aquellos que tienen secundaria completa. Los encuestados, que se dedican a la agricultura desde siempre, consideran regular su condición de vida actual, pues en general su trabajo en esta actividad no es suficiente para solventar los gastos de su familia. Todos los agricultores entrevistados tienen tierras propias, que adquirieron por compra de un particular, con 8 hectáreas de media. En todos esos terrenos hay cultivos agrícolas, con el café absorbiendo de 1 a 6 ha. La comercialización del café es hecha vía intermediarios al mercado local del distrito, siendo vendido en grano.

En el caserío de Alto Belén viven aproximadamente 40 familias de agricultores. Así como en Alto Yacusisa, ahí también se entrevistó 10 agricultores que se dedican al cultivo del café de un total de 35 productores cafetaleros. A través de la encuesta, se puede observar que la mayoría de los agricultores están conformados entre 4 a 5 miembros en la familia y se encuentran en un rango de edad entre los 32 a 50 años, siendo más jóvenes que los productores del otro caserío. El nivel de escolaridad también es bajo, con solo una persona teniendo concluido la secundaria, el resto tiene primaria incompleta. Ellos se dedican a la agricultura y también 
consideran que su condición de vida es regular. Después de la temporada de la cosecha de café, algunos agricultores trabajan para terceros como peones. De los entrevistados, 8 tienen tierras propias que adquirieron por compra de particular y dos adquirieron por donación. El área media de terreno es de 8 ha, pero el café absorbe de 1,5 a 4 ha, y algunos tienen áreas con plátano, yuca y frijoles, principalmente para su propio consumo, y crían animales de corral. En Alto Belén los productores comercializan su café en grano a tiendas locales y algunos comercializan el café molido en tiendas y clientes directos.

Un dato muy importante de Alto Belén es que uno de los agricultores del caserío es presidente de los Cafetaleros del Distrito de José Crespo y Castillo. Él comentó que en 2016 formaron una asociación en el caserio y decidieron en comenzar a procesar su café, alquilando máquinas y comercializando su producto directamente en las tiendas. También como asociación participan en ferias provinciales que organizaba el gobierno regional. En el 2018, consiguieron sus propias maquinarias para el procesamiento de su producto. Mismo organizados, el presidente manifestó que falta el apoyo e incentivo a los campesinos por parte de entidades de la agricultura.

\section{Análisis económico del café en Alto Yacusisa y Alto Belén}

Un primer punto para el análisis económico del café es la producción por hectáreas (rendimiento) que fue obtenida por los productores de Alto Yacusisa y Alto Belén. En el Cuadro 1 se observa que la cantidad mínima producida de café es de $375 \mathrm{~kg} / \mathrm{ha}$ y la cantidad máxima llega a $750 \mathrm{~kg} / \mathrm{ha}$, indicando una gran variación entre productores. En Alto Yacusisa la productividad media de los 10 agricultores fue de $500 \mathrm{~kg} / \mathrm{ha}$, en cuanto en Alto Belén $508 \mathrm{~kg} /$ ha. Es importante decir que este valor está bajo de la media nacional y departamental, y esta diferencia ocurre porque el abonamiento de las plantas no es constante y el mantenimiento se realiza pocas veces, sin un control efectivo de las malezas. 
Cuadro 1 - Área con café, cantidad producida, costo de producción, precio de venta y ganancia neta del café por productor y caserío (2018)

\begin{tabular}{|c|c|c|c|c|c|c|}
\hline \multicolumn{2}{|c|}{ Productores } & $\begin{array}{c}\text { Área } \\
\text { con café } \\
\text { (ha) }\end{array}$ & $\begin{array}{c}\text { Cantidad } \\
\text { producida } \\
\text { (Kg/ha) }\end{array}$ & $\begin{array}{l}\text { Costo de } \\
\text { producción } \\
\text { (US\$/ha) }\end{array}$ & $\begin{array}{c}\text { Precio de } \\
\text { venta } \\
\text { (US\$/kg) }\end{array}$ & $\begin{array}{c}\text { Ganancia } \\
\text { neta } \\
\text { (US\$/ha) }\end{array}$ \\
\hline \multirow{10}{*}{$\begin{array}{c}\text { Productores } \\
\text { de Alto } \\
\text { Yacusisa }\end{array}$} & PAY1 & 2,00 & 500,00 & 811,20 & 1,49 & $-68,04$ \\
\hline & PAY2 & 4,00 & 400,00 & 765.30 & 1,63 & $-111,32$ \\
\hline & $\mathrm{PAY}_{3}$ & 2,00 & 375.00 & 717,50 & 1,93 & 7,07 \\
\hline & PAY4 & 6,00 & 700,00 & 793,04 & 1,63 & 351,42 \\
\hline & PAY5 & 2,00 & 500,00 & 782,48 & 1,49 & -39.33 \\
\hline & PAY6 & 2,00 & 500,00 & 722,74 & 1,49 & 20,42 \\
\hline & PAY7 & 1,50 & 500,00 & 784,27 & 1,63 & 33,20 \\
\hline & PAY8 & 1,00 & 600,00 & 805,05 & 1,63 & 175.92 \\
\hline & PAYg & 3,00 & 400,00 & 782,40 & 1,49 & $-187,87$ \\
\hline & PAY10 & 4,00 & 675,00 & 791,70 & 1,49 & 211,56 \\
\hline \multirow{10}{*}{$\begin{array}{l}\text { Productores } \\
\text { de Alto } \\
\text { Belém }\end{array}$} & PAB1 & 4,00 & 450,00 & 810,78 & 1,78 & $-8,17$ \\
\hline & PAB2 & 3,00 & 500,00 & 681,92 & 1,49 & 61,24 \\
\hline & PAB3 & 4,00 & 500,00 & 794,82 & 1,93 & 171,28 \\
\hline & PAB4 & 3,00 & 483.33 & 774.37 & 1,49 & -55.98 \\
\hline & PAB5 & 2,50 & 600,00 & 803,01 & 1,49 & 88,78 \\
\hline & PAB6 & 1,50 & 466,67 & 823,42 & 1,49 & $-129,81$ \\
\hline & PAB7 & 1,50 & 666,67 & 841,91 & 1,49 & 148,97 \\
\hline & PAB8 & 2,00 & 400,00 & 796,37 & 1,78 & $-82,94$ \\
\hline & PABg & 2,00 & 750,00 & 831,95 & 1,78 & 505.73 \\
\hline & PAB10 & 2,00 & 400,00 & 803,80 & 1,63 & $-149,82$ \\
\hline
\end{tabular}

Fuente: Investigación de campo (2019).

En relación a los costos totales de producción, fueran incluidos los gastos para la implementación de una hectárea de café, el cual fue dividido por 10 años, que es el número de años de producción. Además, se incluyó costos de la mano de obra externa de la finca, como el pago que algunas fincas hacen a los peones que realizan el trabajo de cultivo de café y cosecha; y gastos de actividades desde el almacigo hasta la primera cosecha del café, como preparación de cama y ramada del vivero, llenado y organización de bolsas, siembra de mariposas, preparación de terreno (rozo, tumba y quema), alineamiento y hoyos, trasplante, abonamiento, deshierbo y el control fitosanitario. También se sumaron todos los insumos utilizados, como semillas, bolsas, herramientas para el cultivo y otros.

Conforme el Cuadro 1, hay una relevante variación en el costo total de producción por hectárea entre los agricultores, ya que el costo mínimo es de 681,92 US\$/ha y el costo mayor es de 
841,91 US\$/ha. Además de las condiciones naturales de la finca, que torna necesario más o menos insumos (áreas más fértiles que otras, por ejemplo), también influyen las opciones de invertir más o menos en la producción, o conseguir mejores precios en el momento que comprar insumos o una máquina. En general, los productores con mayores áreas, que compran más productos, o aquellos con mejores condiciones económicas, que pagan a vista, consiguen cultivar su café con menores costos. En comparación de los datos de Huánuco $(1.705,69$ US\$/Kg en 2018), el costo en los caseríos es mucho menor, sobre todo porque utilizan mayormente mano de obra familiar.

Entre los encuestados el precio de venta del café verde varió entre US\$1,49 y US\$1,93 el kilo en 2018. Es importante indicar que la variación ocurre porque algunos comercializan directamente en los mercados del distrito y otros a través de intermediarios, así como interfiere el período de venta (cosecha o fuera de cosecha). Una opinión común de los agricultores es que el precio del café es bajo, siguiendo la media nacional, que estuvo en US\$1,63 en 2018. Pero, en 2019 el valor cayo aún más, siendo comercializado en la chacra a 1,33US\$/Kg en el momento de la investigación de campo.

En una hectárea se puede observar que la ganancia neta con el café varía mucho entre productores. En el caserío de Alto Yacusisa 4 productores tienen perdida y 6 tienen ganancia, con una variación de US\$ -111,32 hasta US\$351,42 por hectárea. En el caserio de Alto Belén la mitad se quedó en prejuicio y mitad obtuvo margen positiva, oscilando entre $-149,82$ y 505,73 US\$/ha. Entre los caseríos, la media se queda muy baja, llegando a 39,30 US\$/ha en Alto Yacusisa contra 54,93US\$/ha en Alto Belén (Cuadro 1). En el caso del productor 9 de Alto Belén, seguido por el cafetalero 4 de Alto Yacusisa, gran parte de su desempeño ocurre por la productividad que alcanza por hectárea, pues no están entre los agricultores que ganan mejores precios en la venta o que tienen menos costos de producción.

De los 20 encuestados, 5 agricultores de Alto Belén también comercializan café molido, por disponer de máquinas para esto, las cuales fueron adquiridas vía asociación. Pero los productores destinan partes diferentes de su producto para industrialización: el PAB2 destina el 44\% de su producción, en cuanto al PAB3 el 30\%, el PAB4 el 80\%, el PAB5 el 33\% y el PAB6 el 67\%. El precio pago por el café molido fue de US\$ 5.95 cada paquete de 200 gramos, siendo destinado principalmente para el mercado nacional, pues venden a grandes tiendas y empresas medianas. El costo de producción, además de los otros costos ya presentados, se concentró en embalaje, bolsas y etiquetas. Como la maquina fue comprada y es mantenida por la asociación, y los productores no pagan para usarlas, no se consideró en el costo la depreciación de las máquinas por ser un gasto de la asociación, que brinda el equipamiento a sus socios para ellos agreguen un valor a su producción (solo se consideró las tasas que ellos pagan para mantenerse asociado). Según los datos recolectados, al vender su café molido, los productores conseguirán aplicar su ganancia neta (Figura 3), con excepción del PAB6.

Con estos datos es posible obtener la ganancia neta total que cada productor alcanzo, considerando toda la producción vendida, sea de café en grano, sea de café molido (Figura 3).En 
términos generales, 8 de los 20 productores no tienen ganancia con la actividad (o sea, la actividad generó una deuda para el productor en 2018), en cuanto que 5 tienen un margen muy limitado (inferior a US\$250,00) y 7 tienen una ganancia mayor, sobre todo por tener mayor rendimiento por área y/o industrializar su café, agregando un valor a su producción. De toda manera, estos datos evidencian la baja remuneración obtenida por la actividad, incluso para este último grupo de productores, pues ningún de ellos llego a una remuneración mensual de un salario mínimo de Perú (US\$ 275,00 o S/ 930,00 en 2018). El agricultor con mayor área y remuneración (PAY4) alcanza, con el café, a una ganancia mensual de US\$176,71 (menos de dos tercios de un salario mínimo).

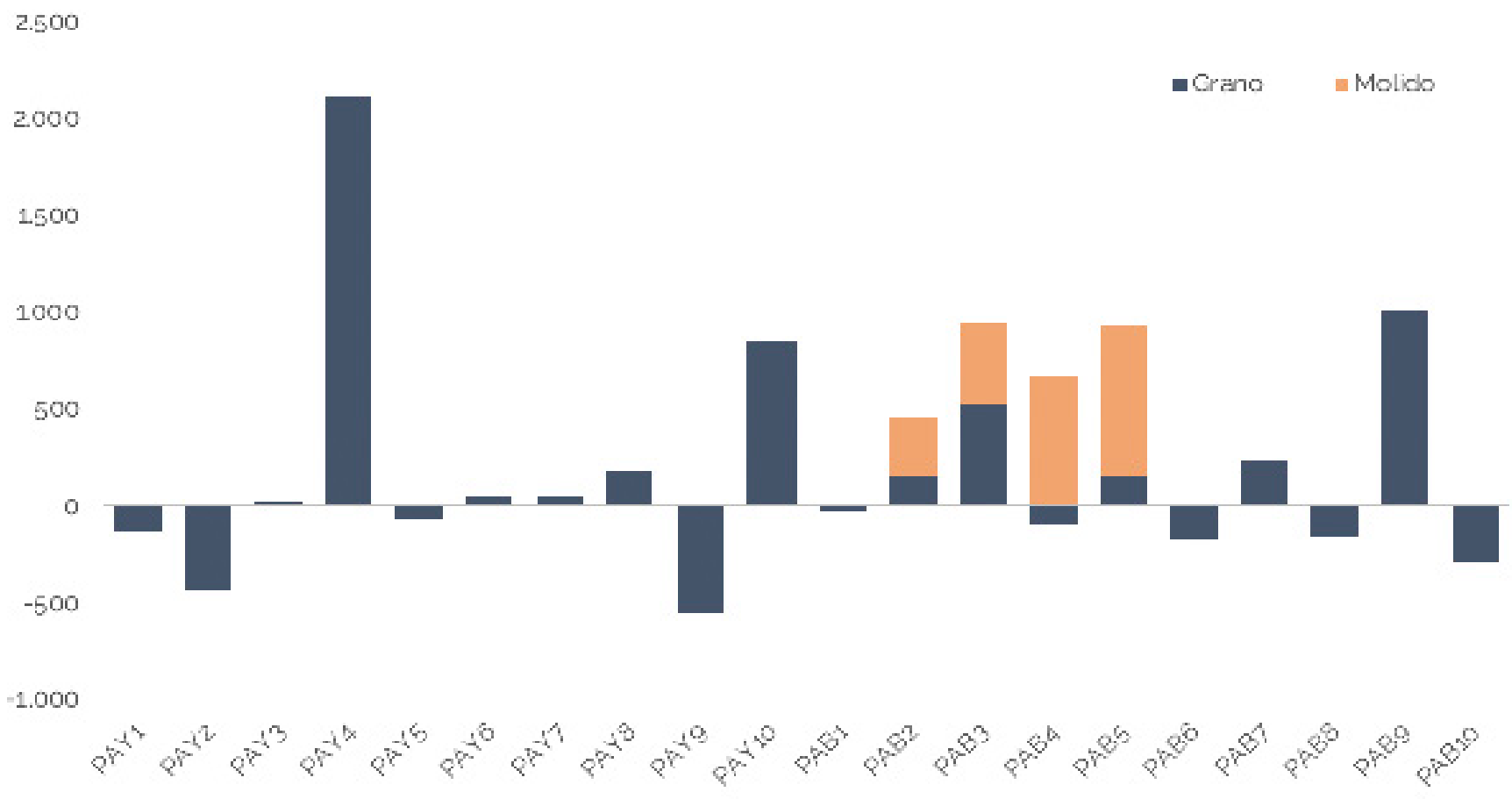

Figura 3 - Ganancia neta total (US\$) de la producción de café (en grano y molido) por productor y caserío (2018).

Fuente: Investigación de Campo (2019).

Entre los principales factores que determinan la rentabilidad de la producción de café, en los distritos de Alto Yacusisa y Alto Belén, está la desvalorización del precio en el momento de comercializar el producto, que tiene influencia directa del contexto internacional, y se refleja en la baja ganancia (o que aumentan la deuda, como es el caso de 8 de los 20 productores encuestados). Esta realidad, como se observó, pasa en diferentes escalas de Perú, afectando de manera directa productores de distintas regiones del pais, pero se muestra más intensa en los caseríos estudiados. Además de esto, es necesario considerar otros aspectos que comprimen la ganancia, como el alto costo de producción, que disminuye las márgenes de 
ganancia, así como las condiciones climáticas, de suelo y ataque de plagas, que impactan en la productividad por área, así como aumentan el costo productivo. También es importante comentar que, durante la investigación de campo, se percibió que muchos productores no realizan un manejo regular de sus cultivos, asi como también tienen mucha dificultad en saber cuánto producen y cuánto gastan en el año (lo que tienen más presente es el precio de venta), lo que evidencia una gestión muy frágil de la finca, que no afecta solo el café, sino todas sus actividades productivas.

\section{Consideraciones finales}

Los resultados de este estudio apuntan que los productores de Alto Yacusisa y Alto Belén (José Crespo y Castillo - Huánuco - Perú) tienen área de cultivo de café que varía entre 1 y 6 hectáreas, con una productividad que oscila de 375 kilos/ha hasta 750 kilos/ha, siendo que este valor está bastante abajo de la media nacional y regional. Es importante mencionar que no existe una fuerte variación del costo de producción por hectárea entre los agricultores, ya que el costo mínimo es de es de 681,92 US\$/ha y el costo mayor es de 841,91 US\$/ha. En términos de precio, hay una oscilación que va de US\$1,49 hasta US\$1,93 el kilo entre los 20 productores.

La ganancia neta calculada en una hectárea tiene mucha variación entre los productores. De los 20 encuestados, 9 tienen pérdida en la comercialización del café en grano, llegando a una deuda de -187,87 US\$/ha. En lo opuesto, la mayor ganancia fue de 505,73 US\$/ha. Como mencionado, esta variación ocurre por la correlación entre rendimiento que cada productor obtiene en sus tierras, el precio recibido por su producción y los costos totales. En los últimos años la caída de los precios internacionales del café afecta de manera directa los productores de diferentes regiones del país, en paralelo al alto costo de producción y a las bajas cosechas. Pero, quien consigue contornar este último punto, es justamente quien obtuvo alguna ganancia en el contexto actual. En cuatro casos se percibe que el procesamiento del café también ofertó un valor agregado a la producción. A pesar de esta iniciativa, lo que se observa en los dos caseríos es una baja ganancia generada por el principal producto agropecuario, manteniendo los pequeños cafetaleros en precarias condiciones económicas.

Como recomendaciones, seria indispensable un proceso de formación de los productores mediante un intercambio de experiencias y conocimientos sobre la relación que existe entre producción, costos y precio de venta, porque al momento de realizar las encuestas los valores que informaban era un aproximado y no sabían si su producción era o no rentable. Este sería un camino que permitiría al agricultor planificar, controlar y tomar decisiones apropiadas para el desarrollo de la actividad. Otro punto es la diversificación de la producción, pues los agricultores de los caseríos tienen una gran dependencia en un solo producto, el cual no les permite ampliar sus ingresos y reducir el alto riesgo económico.

También es imprescindible ampliar el valor agregado del café, avanzando la iniciativa que hace poco se inició en Alto Belén, la cual puede conectarse con la creciente demanda por 
productos que se diferencien por su calidad, origen, forma de producción, etc. Entre los encuestados, la mayoría produce cafés orgánicos, pero no están certificados y no reciben por esta distinción. Otra diferenciación que podría ser utilizada deriva del hecho de que son productores que ingresaron en el café con el intento de salir de un cultivo ilicito, lo que puede movilizar algunos grupos de personas que optan por un consumo politizado. Sería clave, para estos procesos de comercialización, ampliar la organización de estos agricultores, para que puedan alcanzar estos mercados y consumidores diferenciados.

\section{Literatura citada}

Alania Campos, M. H. (2018). Estrutura de governança e mecanismos de coordenação em cadeias curtas de abastecimento alimentar: estudo de caso das organizações dedicadas ao café especial em Villa Rica-Pasco-Peru. Tesis en Desarrollo Rural. PGDR-UFRGS, Porto Alegre.

Becerra Biaggioni, K. (2010). Café de las nubes del Perú. Universidad San Martin de Porres: Fondo editorial.

Cahuapaza, J. (2016). Café orgánico, historia, contexto y perspectivas. Lima: Junta Nacional del Café.

Cámara Peruana de Café y Cacao. (2017). Estudio de mercado del café peruano. Lima: Proyecto café\&clima.

Cárdenas, M. B; Cáceres, E. A; Aulla, F. C; García, G; Peña, E. (2017). Planeamiento Estratégico de los Productores de Café en la Región Junín. (Magíster en Administración Estratégica de Empresas). Pontificia Universidad Católica del Perú. Perú.

Castro, P. et al. Café de especialidad: alternativa para el sector cafetalero peruano. Journal of Economics, Finance and Administrative Science, año 9, n. 17, p. 61-84, 2004.

Conterato, M. A. (2014). O consumo intermediário na agricultura: uma comparação entre agricultura familiar e não familiar no Brasil e nas regiões Sul e Nordeste.Revista Econômica do Nordeste, v. 45, p. 133-162. Recuperado el 26-11-2019 de https://ren.emnuvens.com.br/ren/ article/view/499/395

DRAH - Dirección Regional de Agricultura de Huánuco. (2019). Costos de producción. Recuperado el 16-10-2019 de http://www.huanucoagrario.gob.pe/index.php/2015-05-27-21-2435/costos-de-produccion

González V. E; Espinet C. G. R. (1980). Análisis económico de la producción de café al sol en Puerto Rico. Universidad de Puerto Rico. Puerto Rico.

Guerra, R. U. (1997). El cultivo de la coca en el Perú. In: IX Congreso Nacional de Ingenieros 
Agrónomos. Trujillo. Recuperado el 28-11-2019 de http://www4.congreso.gob.pe/congresista/1995/rurrelo/coca.htm.

INEI. (2013). IV Censo Nacional Agropecuario 2012. Recuperado el 25-11-2019 dehttp://censos.inei.gob.pe/Cenagro/redatam/\#.

INEI. (2019). Estadísticas sectoriales - Agropecuario. Recuperado el 26-11-2019 de https:// WWW.inei.gob.pe/estadisticas/indice-tematico/economia/.

INFOCAFES. Producción de Café en Perú.Recuperado el 02-12-2019 de http://infocafes. com/portal/infocafes/produccion-de-cafe-en-peru/.

La República. (2018). 90\% de la producción del café peruano se exporta. Recuperado el 04-12-2019 de https://larepublica.pe/economia/1304887-90-produccion-cafe-peruano-exporta/.

Leiva-Espinoza, S. T.; Peña, A. R.; Rojas, K. B. R. Caracterización socioeconómica de la producción cafetalera en la provincia de Rodríguez de Mendoza (Amazonas, Perú). Revista de Investigación en Agroproducción Sustentable, v. 1, n. 3, p. 59-67, 2017.

MINAGRI. (2018). Una propuesta de política para una caficultura moderna, competitiva y sostenible. Lima: Fabrica de Ideas, 2018. Recuperado el 25-10-2019 de https://www.undp. org/content/dam/peru/docs/Publicaciones\%20medio\%20ambiente/PNA-Cafe\%20(pliegos)\%20180ct2018\%20(1).pdf.

MINAGRI. (2019). Cafés especiales en el Perú. Recuperado el 25-10-2019 de https://wwW. minagri.gob.pe/portal/especial-iv-cenagro/24-sector-agrario/cafe/204-cafes-especiales-en-el-peru.

Saldaña, T, J, K. (2019). Costos de producción y su incidencia en la rentabilidad del cultivo de café en Aspacoc, Jaen. (Bachiller en Contabilidad). Universidad Señor de Sipán, Perú.

Valera Ríos, K. Análisis de rentabilidad económica del cultivo de la Coca frente a cultivos alternativos (Cacao y Café) en el Distrito de José Crespo y Castillo. Tesis del Departamento Académico de Ciencias Económicas. UNAS, Tíngo Maria, 2010.

Weck, C. Et Al. Cooperativistas y el café nuestro de cada mañana. Medio Ambiente y Urbanización, n. 72, v. 1, p. 75-85, 2010. 